\title{
LA CONFECCIÓN DE LA FIGURA DEL REY GUERRERO EN LAS CRÓNICAS ASTURLEONESAS (SIGLOS VIII-XII).
}

\author{
$M^{a}$ Cristina Redondo Jarillo
}

\section{RESUMEN}

Con este estudio queremos explicar la creación de un discurso en las crónicas asturleonesas, entre los siglos VIII y la primera mitad del siglo XII, que pretende exaltar la figura de la realeza como guerrera. De este modo, podremos comprobar que, en líneas generales, se tiende a utilizar y consolidar la noción marcial de los gobernantes como algo necesario en el contexto dialéctico de la Reconquista. Esta misma pasó a ser entendida como una guerra necesaria para la salvación del reino y su identificación con la Iglesia consagró al adalid asturleonés como caudillo de Cristo en la tarea de la defensa y la restauración.

Palabras clave: rey guerrero, s. VIII-XII, crónicas, reino asturleonés, pensamiento político.

\begin{abstract}
With this paper, we want to explain the speech creation in the asturleonés chronicles between the VIII and the first half of the XIIth centuries, which seeks to exalt the warrior figure of royality. Thus, we can see that, in general, it's tended to use and consolidate the martial rulers notion as necessary in the Reconquest dialectical context. This war became to be understood as necessary for the kingdom survival, and his identification with the Church consecrated asturleonés leader as chief of Christ in the task of defense and restoration.
\end{abstract}

Key words: warrior king, VIII-XIIth centuries, chronicles, asturleones kingdom, political thoght. 
El caudillo de todos fue el rey del imperio toledano; este Alfonso, que ostenta el título de emperador siguiendo las hazañas de Carlos, al que corresponde equipararle: fueron iguales en carácter, parejos en la fuerza de sus armas, igual fue la gloria de las guerras realizadas por ellos ${ }^{1}$.

A principios del siglo XX, el gran hispanista francés L. Barrau-Dihigo planteó que la historia de la alta Edad Media peninsular no ofrecía nada más que meras narraciones de batallas $^{2}$. La Reconquista, que desde el discurso peninsular duró casi ocho siglos, trajo como consecuencia que la producción historiográfica de esas centurias se caracterizase por la abundancia de perfiles militares y una temática que insistía en la necesidad de mantener la contienda. Es cierto que "la guerra ocupó un papel esencial en la formación de la percepción del mundo en la Edad Media" ". Y que, por tanto, fue habitual que la realeza medieval adoptase esta tónica dentro de sus ideales políticos. Pero lo que también es incuestionable es que el contexto peninsular fue clave para reforzar la elaboración de un referente teórico inspirado en la militarización de los gobernantes, y que definió, por encima de los demás reinos de la Cristiandad, los fundamentos de poder de los reyes hispánicos.

La gran mayoría de las veces, la práctica es inspiradora de la teoría ${ }^{4}$. Y en el caso del reino asturleonés, los componentes cronísticos que nos han llegado - mucho más abundantes que en otros reinos - nos reflejan esta perspectiva marcial de sus reyes de un modo particular: como los referentes directos de la salvación peninsular y elevando a sus dirigentes como los únicos adalides en esa pugna 5 .

Esta visión centralizada es consecuencia de la necesidad propagandística que requiere la propia guerra contra el infiel. A fin de cuentas, se trata de una visión creada para legitimar un proceso bélico que fue iniciado por el ideario mozárabe. Tanto en la Crónica bizantina de 741 como en la Crónica mozárabe de 754 se presenta a un mundo islámico cargado de una imagen cruel y brutal ${ }^{6}$. J. Flori ha llegado a utilizar el término diabolización

\footnotetext{
1 PÉREZ GONZÁLEZ, M. (ed.): Crónica del Emperador Alfonso VII, León, Universidad de León, 1997, p. 131.

2 BARRAU-DIHIGO, L.: "Recherches sur l'histoire politique du royaume Asturien (718-910)", Revue hispanique, 52 (1921), pp. 79-106. Cit. en VV. AA.: El reino de León en la alta Edad Media. III. La monarquía astur-leonesa. De Pelayo a Alfonso VI (718-1109), Madrid, Centro de Estudios e Investigación "San Isidoro" (CSIC-CECEL), 1995, p. 11.

3 VARELA AGÜÍ, E.: La fortaleza medieval: simbolismo y poder en la Edad Media, Valladolid, Junta de Castilla y León, 2002, p. 69.

4 FOUCAULT, M.: Un diálogo sobre el poder y otras conversaciones, Madrid, Alianza Editorial, 2004, p. 23.

5 En toda la historiografía asturleonesa es común que se vean a si mismos como los únicos descendientes de ese reino visigodo de Toledo. Porque, como dice J. L. Martín, la reconquista se entiende como "la restauración de la fe cristiana frente al Islam y recuperación de los dominios visigodos, a cargo del rey de Asturias, el sucesor legítimo de Rodrigo que se convierte así en rey único de España con derechos sobre los territorios musulmanes y, también, sobre los cristianos, tanto sobre los rebeldes del interior como sobre los que han formado el reino de Pamplona o los diversos condados pirenaicos, pues según los cronistas nadie resistió tanto salvo los asturianos”. MARTÍN, J. L.: "Reconquista y cruzada”, Studia Zamorensia, 3 (1996), p. 222.

6 Para S. Fanjul esta presentación del mundo islámico es consecuencia de la visión que querían mostrar los mozárabes que, a fin de cuentas, eran “quienes los padecían en directo”. FANJUL, S.: Al-Ándalus contra España. La forja del mito, Madrid, Siglo Veintiuno, 2001, p. 25. Vid. también J. V. TOLAN, Sarracenos. El Islam en el imaginario medieval europeo, Valencia, 2007.
} 
para definir el discurso asturleonés sobre el Islam ${ }^{7}$. Frente a ellos, se fomentó la visión de la realeza asturleonesa como defensora y guerrera. Hasta el punto de que esta militarización exacerbada fue fruto de la posterior definición de los fundamentos regios de esa época. Se produjo, en torno a ellos, una mitificación de la realeza hispana a la que se vinculó directamente con la Reconquista.

Es por ello por lo que cualquier lector que se acerque a las crónicas asturleonesas pueda llegar a pensar lo mismo que el hispanista francés L. Barrau-Dihigo: que únicamente hay relatos de batallas en la historiografía latina de esos siglos; sin pararse a pensar que eso mismo es fruto de una necesidad propagandística y de una concepción de la historia que valora el hecho de armas como elemento esencial de discurso legitimador de la realeza.. De hecho, en la Historia Silense vemos como su redactor es consciente de la abundancia de esta temática militarizada, pero la defenderá frente a otros estilos historiográficos más cortesanos ${ }^{8}$. En este sentido, si los relatos tienen un resultado así es porque, aunque en los demás reinos de la Cristiandad sus reyes se rodeen de este halo militarizado, lo cierto es que se diferencian de los peninsulares en que éstos últimos reciben la idea de que la lucha contra el infiel es "una empresa colectiva, teñida como tal por la realeza" ". Para que esto suceda en el resto de Europa tendremos que esperar al movimiento cruzado ${ }^{10}$. Pero, sobre todo, porque el mundo islámico está presente en sus tierras y, no sólo como invasor, sino como instancia de poder entendida y promovida como radicalmente opuesta a su cultura ${ }^{11}$.

\section{LA REALEZA ASTURLEONESA Y SU DESCRIPCIÓN MILITARIZADA}

Para Julio Trebolle Barrera, la guerra fue siempre “una institución natural”, propia de todas las sociedades, llegando a crear en los periodos primitivos una unión entre sociedad y ejército ${ }^{12}$. Pero, de esta unión surgieron, forzosamente, los adalides de esas tropas y muy pronto se les empezó a vincular con la dirección del propio pueblo. Así, se creó la base que determinó la obligación de la defensa del territorio y sus habitantes. La tierra y su morador dieron entonces sentido a la organización de un poder jerarquizado que, en circunstancias

7 FLORI, J.: La guerre sainte. La formation de l'idée de croisade dans l'Occident chrétien, Paris, Aubier, 2001, p. 246.

$8 \quad$ El autor explica la abundancia de relatos bélicos en la literatura hispánica frente a la carolingia: "Mas los que prosiguen a describir las mansiones de ciertos reyes francos, adviertan que en vez de los natalicios y viandas pascuales que aseguran haber consumido ellos por diversos lugares, nosotros describimos los trabajos y sudores del ejército de los reyes hispánicos para liberar a la Santa Iglesia, no convites y delicados manjares. Para esto reflexionen que los dones con los cuales Carlos había mitigado la rabia de los bárbaros para reducir a los cautivos de sus confines, fueron arrancados de manos de ellos por la victoria del rey hispano". Historia Silense, en Las Crónicas latinas de la Reconquista, A. Huici Miranda (ed.), II, Valencia, Vives Mora, 1913, pp. 74-75.

9 MARAVALL, J.A.: El concepto de España en la Edad Media, Madrid, Instituto de Estudios Políticos, 1964, p. 267.

10 Martín de Riquer “ha observado que los sarracenos (...) de toda la epopeya francesa son personajes pintorescos y arbitrarios (...); todo lo cual revela que el público a quien iba destinada la gesta tenía una vaga y lejanísima idea de lo que era un mahometano”. Ibid..

11 En la Península, el musulmán está definido por su “crueldad, predisposición aleve, cobardía y lujuria”. FANJUL: Al-Ándalus contra España. La forja del mito, ob. cit., p. 26.

12 TREBOLlE BARRERA, J.: "Violencia y guerra en el Antiguo Testamento", Espacio, Tiempo y Forma. Serie II. Historia Antigua, 7 (1994), p. 384. 
de conflicto, transformó a la cúspide del poder en el garante de la defensa frente a las agresiones.

Como hemos apuntado anteriormente, el proceso de la Reconquista fue clave para la elaboración de un programa militarizado. Hecho que no sólo demuestra la importancia del oficio guerrero en la realeza asturleonesa, sino la exigencia propagandística de los cronistas del reino en exaltar esas virtudes. Y a pesar de que, en muchas ocasiones, debido a periodos de escaso enfrentamiento con el islam peninsular, el conflicto se atenúa, es incluso necesario decorar la vida del reino con un cariz militar ${ }^{13}$. Muy acertadamente, $\mathrm{Ph}$. Contamine dijo que "sería muy poco exacto imaginar una Edad Media en constante estado de beligerancia, incesantemente entregada a la violencia" ${ }^{4}$. Pero lo cierto es - y ya lo apuntó el historiador francés - que la sociedad del momento adoptó frecuentemente esta apariencia ${ }^{15}$. Y en el caso peninsular, de forma más acusada por la convivencia continua con ese enemigo político, del que nos habló J. A. Maravall, por la creación temprana de un concepto de frontera, al que se aspiraba a reconquistar, y por la sacralización del hecho mismo de la guerra contra el infiel, representando a los reyes como los defensores y restauradores del reino ${ }^{16}$.

El caso más consolidado es el de Pelayo, ya que en él se reúnen los tres requisitos básicos para la obtención del poder: el don divino, la elección del reino y su herencia goda ${ }^{17}$. De él se dice, en la versión Rotense de la Crónica del Alfonso III, que fue espatario de Vitiza y de Rodrigo ${ }^{18}$. En la versión $A$ Sebastián se pone más énfasis en destacar que es hijo del duque Fávila ${ }^{19}$. Pero, tanto en una como en otra se hace hincapié en su cariz guerrero. En cuanto a su distinción como espatario, no hace falta que insistamos mucho. Pero en lo que atañe a su estirpe, se especifica que era hijo de un $d u x$, esto es de un jefe o señor identificado como ducator y que, por tanto, posee el ducatus; es decir, el mando. Este dux es el guía, el caudillo, el general, que se rodea de todo un componente bélico como conductor de la tropa, a diferencia del comes que, aunque a veces pueda regir un combate, es el compañero de aquel que realmente lo lidera.

Lo más interesante de todo esto es cómo se identifica a Pelayo como princeps. El término varía y es utilizado o no de forma indiferente sobre los demás reyes asturleoneses.

13 Para J. L. Martín, la visión militarizada expuesta por los clérigos cristianos en las crónicas asturleonesas se contradice con el cobro de parias al que aluden en sus escritos los cronistas musulmanes. MARTÍN, "Reconquista y cruzada", art. cit., p. 233.

14 CONTAMINE, PH.: La guerra en la Edad Media, Barcelona, Labor, 1984, p. 387.

15 Ibid. En este sentido, E. Varela ha afirmado acertadamente que la asunción de estas categorías definitorias de la propia sociedad "se produce de una manera inconsciente; la sociedad en su conjunto no las impone de una manera deliberada a los individuos sino que se trata de una imposición inconsciente y de una absorción igual de inconsciente por parte de los miembros de la sociedad. Las categorías de una cultura son las que conforman ese modelo del mundo e impregnan todas las manifestaciones de la sociedad, son categorías conceptuales determinantes de la conciencia humana”. VARELA AGÜÍ: La fortaleza medieval, ob. cit., p. 66.

16 Frente a ello resulta paradójica la realidad. Por todos es sabido lo habitual que era entre los reyes peninsulares someter a las tierras conquistadas a tributo y vasallaje, cosa que resultaba extraña a los cruzados europeos. Vid. MARTÍN: "Reconquista y cruzada", art. cit., p. 226.

17 Con respeto a estos tres principios Vid. MARAVALL, J. A.: Estudios de Historia del Pensamiento Español, Madrid, Cultura Hispánica, 1966, p. 35.

18 Crónica de Alfonso III (versión Rotense), en Crónicas Asturianas, J. Gil Fernández y J. L. Moralejo (eds.), Oviedo, Universidad de Oviedo, 1985, p. 200.

19 Crónica de Alfonso III (versión A Sebastián), en Crónicas Asturianas, J. Gil Fernández y J. L. Moralejo (eds.), Oviedo, Universidad de Oviedo, 1985, p. 201. 
Sin embargo, la expresión es utilizada con Pelayo en todas las crónicas y como definitoria de lo que simboliza su persona. Al usar de forma concluyente el título de princeps, frente a la opción de rex, lo que se está intentando decir es que Pelayo ha sido elegido como el primero de todo un linaje posterior, que protagonizará la lucha restauradora. Eso no quiere decir que antes de él no existieran caudillos que detentasen el poder de algunas zonas de Asturias $^{20}$. Pero, lo que está claro es que el mito de Pelayo se convirtió, con el paso del tiempo, en el núcleo idealizado de lo que ellos entendían como su comunidad ${ }^{21}$. Así pues, se utiliza la definición guerrera de los nuevos gobernantes como punto de inflexión entre un periodo y otro, y se inicia una nueva fase caracterizada por la necesidad de reconquista de la tierra perdida ${ }^{22}$.

Todo este componente militar no hay que analizarlo de forma individual, ya que en muchas ocasiones va unido a otro de los discursos utilizados para la exaltación del gobernante en la Edad Media: la sabiduría. Se mantiene, de este modo, la dualidad antropológica de tradición homérica analizada por el filólogo alemán E. R. Curtius ${ }^{23}$, y que no está excluida de las crónicas asturleonesas. Este ideal griego se fundamenta en la idea de que la fortaleza y el buen quehacer de las armas están ligados a la sabiduría y a la prudencia en la ciencia de la guerra ${ }^{24}$.

Pero lo más llamativo de todo esto es que por la adquisición de esa dualidad sobre los reyes leoneses, lo que se consigue es que sus cronistas terminen equiparando a sus gobernantes con los héroes de la Antigüedad. El Silense nos describe de este modo a Alfonso VI, ya que la propia historia es toda una alabanza a la figura del emperador. Nos lo presenta glorificando su "magna fuerza" y su buen "consejo de las armas". Pero, al mismo tiempo lo heroifica cuando explica que esta unión entre fortaleza y sabio consejo "entre los mortales apenas se encuentra. Pues lo uno parece proceder del temor de la muerte y lo otro de la audacia de la fortaleza" 25 . Esta característica dual de la sapientia et fortitudo lo que consigue es elevar a un rango superior a sus depositarios, convirtiendo en héroes a los reyes y sacralizándolos al distinguirlos del resto de los hombres.

La equiparación de los gobernantes medievales con los héroes hace que se rodeen de toda una aureola legendaria ${ }^{26}$. Así, se justifica la necesidad de escribir sus hechos,

20 Para ver estos primeros caudillos indígenas Vid. BARBERO, A. y M. VIGIL: La formación del feudalismo en la Península Ibérica, Barcelona, Crítica, 1991, p. 337.

21 MARAVALL, El concepto de España en la Edad Media, ob. cit., p. 257.

22 Queremos dejar claro que en todo momento estamos hablando de fuentes cronísticas, como se ha indicado al principio del estudio. Porque en cuanto al uso del término princeps en la documentación astur vemos que es más frecuente. M. Gómez Moreno entendió su empleo habitual como "una pretensión menor que la de llamarse reyes". J. A. Maravall aporta, al respecto, una serie de ejemplos que confirman la asiduidad del término en la documentación regia hasta el siglo XI. A partir de entonces, el título de rex empezará a ser más corriente en los diplomas. Vid. MARAVALL, Estudios de Historia del Pensamiento Español, ob. cit., pp. 26-27.

23 CURTIUS, E. R.: Literatura europea y Edad Media Latina (I), Madrid, Fondo de Cultura Económica, 1981 , pp. 242-262.

24 “... los griegos consideraron siempre la destreza y la fuerza sobresalientes (...). La noción de valor presuponía la fortaleza física y moral, y junto con la destreza y el arrojo militar, conformaban los fundamentos de la nobleza caballeresca, que se resumían en el concepto de la areté, el ideal y atributo propio de la nobleza aristocrática griega”. VARELA AGÜÍ, La fortaleza medieval, ob. cit., p. 69.

25 Historia Silense, ed. cit., pp. 20-21.

26 FERNÁNDEZ, E.: "Héroes y arquetipos en la iconografía medieval”, Cuadernos del CEMYR, 1 (1994), p. 13. 
como los de los protagonistas de la literatura épica de la Antigüedad ${ }^{27}$. Se trata, pues, de una mitificación de los reyes, alzados como paradigmas virtuosos y enlazados con los modelos de la Antigüedad. Pero lo cierto es que unos reyes destacan sobre otros en sus hazañas bélicas. De este modo, se mitifica a ciertos gobernantes frente a otros y se les presenta en la historia como los grandes campeones de la Reconquista peninsular. Es el caso de Ordoño II. Su ascenso al trono viene motivado por la prematura muerte de su hermano García. El Silense explica su formación militar como prefecto en Galicia y le presenta como un buen defensor para el reino ${ }^{28}$. Y sigue diciendo como esta virtud guerrera era propia de su estirpe y de seguir las enseñanzas de su padre Alfonso III $^{29}$, al cual tanto el cronista como la historia anterior ya le han definido como magnus rex.

Volviendo con Ordoño II, lo cierto es que la aureola marcial que le rodea en los escritos supuestamente es consecuencia de su propio cariz, "pues era próvido y prudentísimo en toda guerra" ${ }^{30}$. Además, se le denomina Odonius belliger ${ }^{31}$ y la verdad es que en todas las crónicas se le destaca ampliamente por sus virtudes militares sobre cualquier otro. De hecho, es un rey que, según el Silense, debía tener muy claro que su primer oficio era la guerra $^{32}$ y que éste no debía entorpecerse por el ocio, tan abundante en las narraciones de los reyes francos ${ }^{33}$. Y predicará con el ejemplo con sus varias campañas a Évora y a Mérida. A la primera de ellas, "ni le sirvió la robustez de sus muros ni la fuerte tropa de guerreros para que no se sometiese al instante a la victoria de Ordoño, fortísimo soldado" 34 .

En estas narraciones sobre las campañas de la Reconquista se da una tónica común: la exageración desmesurada de los cronistas al presentar unas victorias, a simple vista, fáciles, en las que el factor devastador, protagonizado por la figura del gobernante es un recurso político para elevarle de forma hiperbólica como un gran caudillo. Esto es consecuencia de la identificación del rey asturleonés como strenuus por sus formas diligentes y resueltas en la guerra, gracias a su valentía, esfuerzo y formación como guerrero.

Por todos es sabido que el mejor recurso de la historiografía latina medieval para presentar una gran victoria es describir la devastación que vino con ella. Así, encontramos que tras la presencia del rey cristiano vencedor, queda un rastro de destrucción, incendio

27 La Crónica del Emperador Alfonso VII tiene muy clara esta idea cuando nos dice, en el prefacio de la misma, que "puesto que la historia del pasado escrita por los historiógrafos y transmitida por medio de la escritura para recuerdo de la posteridad, renueva los antiguos hechos memorables de los reyes y emperadores, de los grandes señores y de otros héroes...”. Al decir otros héroes deja claro que está englobando a todos los citados en esa categoría. Crónica del emperador Alfonso VII, ed. cit., p. 61.

28 Historia Silense, ed. cit., p. 86.

29 Ibid.

$30 \quad$ Ibid., pp. 87-88.

31 Ibid., p. 89.

32 Para J. A. Maravall el rey de la Edad Media peninsular "aplica su potestad a un fin general: poblar, reconquistar, defender al pueblo, ampliar y fortalecer el reino”. MARAVALL, Estudios de Historia del Pensamiento Español, ob. cit., p. 26.

33 Historia Silense, ed. cit., p. 93.

34 Ibid., p.88-89. 
y muerte ${ }^{35}$. Y, aunque en ocasiones la realidad no fuese tan convulsa como la propaganda de los reinos cristianos nos presenta, lo cierto es que la literatura política de este periodo necesita revestirse de estas técnicas.

A todo esto hay que añadir el recurso hiperbólico de numerar a los enemigos muertos. En este sentido, las cifras responden a proporciones excesivas, traspasando los límites de lo que seguramente fue la realidad. En este sentido, el Silense es muy significativo: en la batalla de Covadonga (722) se mataron a 124.000 caldeos $^{36}$; Fruela I, a 54.000 del ejército cordobés que intentaba atacar Galicia en el 75737; Alfonso III en el 868, a 416 en el enfrentamiento con la parte del ejército de al-Mundir que se dirigía a León ${ }^{38}$, y a 3.565 con el resto que estaba en el Bierzo $^{39}$. Aunque el que se lleva la palma es, por supuesto, Ordoño II que en la batalla contra las tropas de Abd-al-Rahman III, en San Esteban de Gormaz (917), mató a tantos enemigos que "si algún investigador de los astros intentase contar tantos miles de moros, en verdad el número excedía a todo modo por la multitud de los cadáveres" 40.

Se trata, a fin de cuentas de magnas caedes, como en muchas ocasiones las definen los cronistas. Es decir, de grandes carnicerías o matanzas desmesuradas, que traspasan los límites de lo verdadero, pero que terminan siendo otro recurso más en este discurso político. Con estas representaciones beligerantes se marcan dos ideas clave para los receptores del mensaje. En primer lugar, que el reino en guerra contra el infiel está defendido por estos dirigentes experimentados en las armas. Y, en segundo lugar, que la eficacia militar de los reyes y sus victorias son dignas de exaltación. Aunque en al-Ándalus la recepción del mensaje no sea esa, la intención es mostrarlos de este modo por el cronista para dar a los habitantes del reino una idea de seguridad gracias a su campeón. Y a los posibles lectores de otras formaciones políticas, exponer a sus adalides como la mano efectiva de la Cristiandad, en una lucha sacralizada.

\section{LOS RECURSOS LITERARIOS PARA LA SACRALIZACIÓN DEL REY GUERRERO EN LAS CRÓNICAS ASTURLEONESAS}

El discurso cronístico asturleonés que se crea entre los siglos VIII al XII sigue una pauta generalmente común, ya que la figura del rey aparece como depositaria del favor

35 Un buen ejemplo de ello lo encontramos de nuevo con Ordoño II en la campaña de Mérida (914) donde aparece el esquema típico de descripción que utilizan los cronistas. En la Crónica Najerense (ed. ESTÉVEZ SOLA, J. A., Madrid, Akal, 2003, p. 128) se nos dice que el rey leonés, "tras arrasar con atroz acometida la provincia entera, invadió la aldea de Culebra”. Y que "muertos los bárbaros de allí encontró, alambró para su patria con sus mujeres e hijos junto con una inmensa carga de oro y plata y de ornamentos de seda. Todos los emeritenses con el rey de la ciudad de Badajoz le salen al paso e inclinados y postrados, implorándole la paz sumisamente, le ofrecieron innumerables regalos. Y así, vencedor y cargado de botín, vuelve a la provincia de los Campos Godos". O en la Historia Silense (Historia Silense, ed. cit., p. 88-89) donde en la primera incursión a Évora (913) se dice del mismo Ordoño que "no sólo tomó la ciudad, sino que mató a todos los que salieran a la pugna con el jefe Zuit. Y habiendo arrebatado los despojos de todos los ciudadanos, vuelve alegre a su propio país con magna turba de cautivos".

36 Historia Silense, ed. cit., p. 52.

37 Ibid., p. 56.

38 Ibid., p. 82.

39 Ibid.

40 El Silense describe esta matanza asegurando que desde el Duero hasta el castillo de Atienza y Paracuellos el campo se cubrió de muertos. Historia Silense, ed. cit., p. 94. 
divino. Así, de Alfonso III se dice que tenía "siempre, desde el inicio de su reinado, el favor de la victoria sobre sus enemigos" ${ }^{11}$; de Ordoño II que "dio el Señor al Católico rey el triunfo" ${ }^{22}$; o de Ramiro II a quien "ayudando la divina clemencia, el Señor le dio la victoria" 43 . Es decir, al cariz strenuus de los reyes asturleoneses se une el magno consilio en la victoria contra al-Ándalus, incluso, protegiendo al adalid en la batalla ${ }^{44}$.

El refuerzo de la presencia de Dios se incentiva con la idea de sentirse un pueblo elegido, aunque castigado por la insolencia de sus últimos reyes godos. Sin embargo, la divina clemencia les permite la recuperación de un territorio sacralizado que consideran suyo. Y, ante ello, el dirigente terrenal de ese pueblo, el rey, recibe más que ningún otro la obligación de llevarles a la salvación y a la victoria. La liberación del reino se entendió como la liberación de la Iglesia - aunque tendremos que esperar hasta mediados del siglo XI para que se identifique a ésta con la de Roma-. Y, por eso se sacralizaron los momentos claves del proceso. Así, la revuelta de Pelayo y sus hombres fue vista como algo inspirado directamente por Dios ya que "se aprestó a poner en práctica lo que ya tenía pensado en torno a la salvación de la Iglesia" 45.

En la alta y la primera plena Edad Media la imagen del Dios que está presente en la sociedad es la del Antiguo Testamento. Y por tanto, no es de extrañar que lo que nos encontremos en las crónicas asturleonesas sea una divinidad muy militarizada. Según J. Trebolle Barrera, "la raíz `ph expresa en hebreo la cólera”. Además, "la antropología bíblica y semita sitúa la sede de la cólera en las narices" ${ }^{46}$. Lo curioso de todo esto es que en el Antiguo Testamento el término 'anaph, es decir, enfadarse, aparece aplicado en numerosas ocasiones a Yahvéh ${ }^{47}$. Lo que ocurre es que no es lo mismo que un mortal se enfade a que lo haga una divinidad. Porque en ese caso, la cólera divina siempre va seguida de cierto espectáculo cósmico y artificiero ${ }^{48}$.

El enfado de la divinidad siempre está motivado por algún hecho injusto ya que "en la narrativa bíblica (...) la violencia es un factor religioso de reinstauración de la justicia violada" ${ }^{49}$. Y esto trae como resultado que Dios actúe como vengador del atropello, con un talante agresivo, marcial, militarizado ${ }^{50}$.

41 Crónica Albeldense, en Crónicas Asturianas, J. Gil Fernández y J. L. Moralejo (eds.), Oviedo, Universidad de Oviedo, 1985, p. 250.

42 Crónica de Sampiro, ed. cit., p. 275.

43 Ibid., p. 285.

44 Es el caso de Ordoño II, del que se nos dice en la Historia Silense que estaba protegido por el escudo de Cristo. Historia Silense, ed. cit., p. 95.

45 Crónica de Alfonso III (versión Rotense), ed. cit., p. 202.

46 TREBOLLE BARRERA: "Violencia y guerra en el Antiguo Testamento", art. cit., p. 389.

47 Según J. Trebolle Barrera, "el verbo ’anaph (...) viene aplicado a Yahvé en 14 ocasiones. Más frecuente es el uso del sustantivo de la misma raíz, que de un total de 278 usos, es referido a Yahvé en 183”, Ibid., p. 289.

48 "El Señor en persona viene de lejos, arde su cólera con espesa humareda; sus labios están llenos de furor, su lengua es fuego devorador; su aliento es torrente desbordado que alcanza hasta el cuello, para cribar a los pueblos con criba de exterminio... El Señor hará por la majestad de su voz, mostrará su brazo que descarga con ira furioso y llama devoradora, con tormenta y aguacero y pedrisco. A la voz del Señor se acobarda Asiria, golpeada con la vara... Que está preparada hace tiempo en Tofet... una pira con leña abundante, y el soplo del Señor, como torrente de azufre, le prenderá fuego”, Isaías 30, 27-33; Cit. Ibid, p. 391.

49 Ibid., p. 392.

50 En Deuteronomio 32, 41-42 tenemos un buen ejemplo de esta imagen: "Cuando afile el relámpago de mi espada y tome en mi mano la justicia, haré venganza del enemigo y daré su paga al adversario; embriagaré mis flechas en sangre, mi espada devorará la carne; sangre de muertos y cautivos, cabezas de jefes y enemigos". Cit. Ibid., p. 389. 
Ejemplos de la ayuda de Dios lo encontramos en la lucha contra Almanzor. Durante el ataque del adalid andalusí a la ciudad de León, en el otoño de 981, Ramiro III, aún a pesar de ser un niño, saldrá armado a su encuentro con sus condes. Y "trabado en el combate, lo postró con gran mortandad contra las tiendas”. Pero, Almanzor no se amilanará y volverá otra vez a la carga. Esta vez, el Silense señala que se consiguió frenar su segunda envestida con una "ingente nieve con torbellino" que Dios lanzó desde el cielo ${ }^{51}$. Pero esta será la última vez que Dios intervenga para frenar a el victorioso. A partir de entonces, y durante la década siguiente, el caudillo árabe asolará el reino leonés hasta que fallezca. Eso sí, según el cronista, esa muerte también será fruto de la divina clemencia ${ }^{52}$.

Durante esos años, Almanzor recorrerá toda la Península sin que nada le frene en su embestida. Sin embargo, habrá algo que le hará sacudirse. Se trata de otro de los métodos que utiliza la divinidad para intervenir en la lucha sacralizada contra el Islam: los santos guerreros. En este caso, se dice que el victorioso "había dispuesto ir al sepulcro del apóstol [Santiago] para que lo fracturase, pero aterrado se volvió" 53 .

A pesar de que la leyenda de Santiago matamoros se fraguó muy pronto en el reino asturleonés, lo cierto es que tendremos que esperar hasta la redacción de la Historia Silense para ver incorporado al apóstol por vez primera en las crónicas. Sin embargo, la imagen que nos llegará de él estará ya muy popularizada ${ }^{54}$. La aparición milagrosa del santo será el resultado de la devoción de un rey sacralizado como Fernando I. La leyenda se centra en los días previos de la toma de Coimbra en 1063 por el rey leonés. El Silense nos cuenta cómo Fernando I estuvo rezando durante tres días, pidiendo "al apóstol ser intercesor por él ante la divina majestad" 55 . En su oración "pedía ser arrancada aquella ciudad de los ritos de los paganos y ser devuelta a la fe de los cristianos" ${ }^{56}$. Así, el apóstol, "soldado de Cristo" ${ }^{7}$, intercede ante Dios para responder a las súplicas del rey leonés.

Santiago vaticinará en Compostela la victoria de Fernando I ante un peregrino griego, escéptico por el componente militar del apóstol ${ }^{58}$. De este modo, con la presencia de los restos de uno de los compañeros de Cristo y sus apariciones en la Reconquista peninsular

\footnotetext{
$51 \quad$ Historia Silense, ed. cit., p. 103.

52 Ibid., p. 105.

53 Ibid., p. 99.

54 CASARIEGO, J. E. (ed.): Crónicas de los Reinos de Asturias y León, León, Everest, 1985, p. 150.

55 Historia Silense, ed. cit., p. 133.

56 Ibid.

57 Ibid., p. 135.

58 Según el cronista, el peregrino criticaba a los feligreses que llamaban a Santiago bonum militem. Entre otras cosas, porque, acertadamente, apuntaba que nunca había sido caballero. Sin duda, esta crítica debía estar muy presente en la época, ante la evidencia bíblica de que Santiago había sido Apóstol de Cristo, pero no un guerrero. Será el mismo santo el que zanje esa disputa con un milagro de índole militar. El Silense nos dice que el peregrino tenía la costumbre de pernoctar en la oración. Y “de súbito, arrebatado con éxtasis, el apóstol Jacobo se le apareció como teniendo ciertas llaves en la mano y hablándole con alegre rostro dice: "Ayer riéndote de los píos votos, de los rogadores, creías nunca haber sido yo valentísimo caballero». Y diciendo estas cosas, fue traído ante las puertas de la iglesia" un caballo blanco. "Al cual ascendiendo el apóstol, notificó al peregrino habiendo mostrado las llaves, haber de dar él la ciudad de Coimbra al rey Fernando para el día siguiente, cerca de la tercera hora del día”. El peregrino, asustado, corrió a avisar al personal religioso de la sede compostelana. Y éstos mandaron rápidamente emisarios para notificar a Fernando I del mensaje del milagro. Pero, cuando llegaron los mensajeros, el rey ya había tomado la ciudad, justo en el día y en la hora en que lo había anunciado el apóstol. Ibid., pp.135-137.
} 
- mucho más utilizadas en las crónicas y en la iconografía a medida que nos vayamos adentrando en los siglos plenomedievales ${ }^{59}-$, lo que se consigue es sacralizar el conflicto contra el mundo islámico. La presencia de estos santos en contextos militares refuerzan la idea de que se trata de una guerra querida por Dios ya que, no sólo se compone de los elementos que la justifican, sino que además se irá convirtiendo en un conflicto con tintes de cruzada, sobre todo a partir del último cuarto del siglo XI.

A la intervención de Dios y de Santiago debemos añadir las donaciones a la Iglesia. Se nos cuenta que el rey Fernando I "siempre proveía con diligente cuidado que de los despojos de sus victorias la mejor parte se distribuyese por las iglesias y pobres de Cristo para alabanza del Sumo Artífice, que lo hacía victorioso" ${ }^{60}$. Pero, entre las donaciones vinculadas a la Reconquista, la que destaca por encima de todas es la llamada Cruz de la Victoria, donada por Alfonso III a San Salvador de Oviedo ${ }^{61}$. Esta cruz sacralizaba directamente la función regia. De hecho P. Schramm nos recuerda la leyenda que la rodeaba. Se decía que era una reliquia de los primeros momentos de la Reconquista y que Pelayo "había llevado ante sí, en su lucha contra los moros, el alma de madera de esta Cruz de la Victoria, cuya figura le había mostrado el Cielo, antes de la batalla de Covadonga" 2. $\mathrm{Y}$ es que, como hemos ido viendo a lo largo de estas líneas, la sacralización de la figura de Pelayo es constante en toda esta simbología. A él se le considera como "lleno de gracia de Dios y de fortaleza" ${ }^{63}$. Y, del mismo modo, los relatos de la batalla de Covadonga se revisten de la misma atmósfera mesiánica ${ }^{64}$. La contienda se entiende como ineludible. Y las consideraciones religiosas a las que se alude sacralizan el inicio del proceso, no sólo entendiéndolo como necesario para el reino, sino también para la salvación de la Iglesia hispana, aunque en sus argumentos ambos están irreversiblemente unidos.

Así pues, en este proceso de sacralización del adalid que dirige la Reconquista, los cronistas han partido de la base de la identificación del proceso de lucha con el dirigente político. Como hemos visto, se entiende la pugna contra el islam dentro de un proceso de reconversión espiritual al que debe someterse el pueblo cristiano. En este sentido, la pérdida de España y la instrumentalización de al-Ándalus, como herramienta divina para castigar al reino, son vistos como forma de perdón de los pecados. Pero, al mismo tiempo,

59 Según E. Varela Agüí "son abundantes las manifestaciones, especialmente escultóricas, donde el fenómeno de la violencia aparece representado en las iglesias - especialmente a partir del siglo XII - con variable temática: desde las recurrentes escenas bíblicas y los santos especialmente como Santiago, San Miguel o San Jorge, hasta las más - o quizá no tanto - sorprendentes imágenes del caballero victorioso, la paz y la tregua de Dios”. VARELA AGÜÍ: La fortaleza medieval, ob. cit., p. 73..

60 Historia Silense, ed. cit., p. 131.

61 “... ofreció al venerable lugar una eximia cruz de puro oro y varias perlas preciosas”, Ibid., p. 87.

62 SCHRAMM, P.: Las insignias de la realeza en la Edad Media española, Madrid, Instituto de Estudios Políticos,1960, p. 20.

63 Historia Silense, ed. cit., pp. 51-53.

64 A la propuesta de Opas de que deponga su resistencia, el caudillo astur responde diciendo: "Cristo es nuestra esperanza de que por este pequeño monte que tu ves se restaure la salvación de España y el ejército del pueblo godo. Pues confío en que se cumpla en nosotros la promesa del Señor que fue dicha por David: «Revisaré con la vara sus inquinidades y con el látigo sus pecados; pero mi misericordia no la apartaré de ellos». Y ahora yo, fiado en la misericordia del Jesucristo, desdeño a esa multitud y no la temo en absoluto. En el combate con que tú nos amenazas, tenemos por abogado ante el Padre al Señor Jesucristo, que poderoso es para librarnos de esos pocos" Crónica de Alfonso III (versión Rotense), ed. cit. p. 204. 
los cronistas rodean a todo este proceso con un componente épico que hace que se sacralice la Reconquista como una pugna para la liberación de la Iglesia. Ésta es identificada con el propio reino al que pertenecen y, por tanto, su dirigente político se verá afectado también por ella. Y, así, finalmente, el discurso de intervención divina, con su ayuda y la de los santos guerreros, sacralizan la figura ya mitificada del rey alzándolo como guerrero de la divinidad.

\section{A MODO DE CONCLUSIÓN}

A través de estas líneas hemos asistido a los distintos recursos discursivos que utilizan los cronistas asturleoneses para presentar a su dirigente como un rey guerrero. Como dijimos al principio del estudio, esta imagen es un recurso muy utilizado por la realeza de la Edad Media. Pero, en el caso peninsular, la Reconquista fue clave para la asunción de este concepto. Los cronistas de la alta y plena Edad Media asturleonesa fueron conscientes en todo momento de su contexto y crearon un sentimiento de particularidad que les hacía sentirse únicos frente a los demás reinos. Y, por tanto, esa distinción se aplicó también a sus reyes.

Se creó una idea de continuo estado de lucha que fue aplicada por los medios de creación cultural en los mensajes que lanzaban. Y, al tiempo de reforzar la imagen contra el enemigo islámico, se consolidó la noción marcial del adalid cristiano de esa lucha. Así, los cronistas empezaron a definir a sus reyes con tintes mucho más militarizados. Términos como providus, belliger, bellicosus o strenuus llenaron las descripciones de los dirigentes políticos en las crónicas. Y, como consecuencia de ello, el componente épico se empezó a implantar sobre los reyes, heroificando su figura, distinguiéndoles del resto de la humanidad, mitificándolos...

La Reconquista pasó a ser entendida como una guerra necesaria para la salvación del reino, y la identificación de este mismo con la Iglesia consagró al rey guerrero asturleonés como caudillo de Cristo en la defensa y restauración. Por ello, la Reconquista se entendía como un acto al que estaban obligados los reyes asturleoneses, como un oficio que determinaba la necesidad de la defensa ante el peligro invasor y como una guerra santificada que sacralizaba a su adalid.

Volviendo al principio de nuestras líneas, decíamos en la introducción al estudio que L. Barrau-Dihigo mostraba su desencanto por la cronística astur, a la cual se la veía como llena de relatos de batallas. Quizá después de lo expuesto podamos entender que ese conflicto continuo del que se rodeó la literatura de esta época fue, además de un gusto por la temática épica, un interés por expandir la visión de una península inserta en un proceso militarizado, pero sacralizado por la idea de sentirse como pueblo elegido y destinado a reinstaurar de nuevo lo que entendían como $s u$ reino. 